\title{
Curriculum Option for Gender Equality: A Channel for Social and Economic Securities in Nigeria
}

\author{
Musa Mohammed Mande, \\ Faculty Of Technology Education, Educational Foundations Department \\ Abubakar Tafawa Balewa University Bauchi
}

\begin{abstract}
Gender inequality has been one of the major forces that threatens the security and economic development of many societies world ever. Nigeria is not an exception in these social vices, where women are not avail with the opportunity to render their services for the general growth of the nation. This paper attempts to advance a curriculum option, that will provide women with the potentials to give their contributions in social and economic developments, that will translate into a positive security atmosphere in Nigeria.
\end{abstract}

\section{Introduction}

The critical role women play in partnership with men in creating and implementing a sustainable pattern of development, has in recent years become a topical issue world over. This is in recognition of the importance, the women play in the process of creating a well balanced society, with a view to make the world a better place to live. Nigeria as a nation cannot be an exception in this positive movement. The neglect women experience from development partners, in terms of their needs, has been the reason for the deterioration of the environment, in the developing nation like Nigeria. This trend has been one of the causes of failure in our developmental process. This has amplified women's voices and strengthened their call for a sustainable future for their children and generation to come. This movement by women to redefine development, has motivated planners to take a wholistic approach that will incorporate women in sustainable development. However, this approach has not considered curriculum option in this direction.

The 1991 global assembly of women and the environment (British council, (1998) sponsored by the United Nation's Environment Programme (UNEP) which invited representatives of both government and nongovernmental organizations to Miami, Florida to confer with 215 women who have initiated successful environmental projects in communities all over the world. These women, many of them faced daily with the responsibility for feeding and protecting the health of their families, took action within the spheres of influence traditionally open to them. They designed smokeless stoves, solar cookers, solar green houses, others are, how to clean up local water suppliers, altered farming methods and successful cultivated degraded lands.

Women are also giving immeasurable contributions in development through their work with nongovernmental organization (NGO's) when the non-government organization sponsored the world women's congress for a healthy planet, also in Miami, Florida over 1,500 women and men from more than 75 countries engaged in a spirited exchange of views on a variety of environmental related issues. The communiqué offered three guiding principles.

1. Global equity giving priority to meeting the basic human needs of people

2. Resource ethics, calling for sustainable use of natural resources and responsibility towards future generations.

3. Empowerment of women at all levels to the achievement of principles of equity social justice.

The world is in desperate need of the good sense, determination and compassion exhibited by women in these international conferences. It is becoming increasingly clear that the talent and capabilities of women have been seriously undermined. Hence, if women are fully educated, through our curriculum provisions, they would have participated in decision-making process and policy making at all levels of the society.

\section{Gender Descrimination Issues In Nigeria}

Gender discrimination is the systematic unfavourable treatment of individuals on the basis of their gender, which denies them rights, opportunities or resources (Seager, 1997) globally women are treated unequal and less value in their lives because of their gender. This attitude is more pronounced in developing countries like Nigeria, where women experience discrimination even within the family, society and government levels. The most extreme gender discrimination can lead to son preference expressed to sex selection, in the labour market, unequal pay, occupational exclusion or segregation, limit women's earning in comparison to men of similar education. Women lack representation and voices in decision making bodies in our communities and government. If these trend is not checked, the role of the woman folk in national development, will be greatly undermined. 


\section{(a) Gender division of labour}

Anker, (1997) defined gender division of labour as socially determined ideas and practices which defined what roles and activities are deemed appropriate for women and men. In most cases, roles designated as female are less valued than those designated as male. Women generally perform the reproductive roles of bearing and raising children, caring for family members and house hold management. While men do the productive role of paid work and market production. The roles of women in Nigeria are gradually rising, but are restricted to a narrow range of occupation.

\section{(b) Gender equality and equity}

Gender equality and equity denotes women having the same opportunities in life as men including the ability to participate in public spheres (Development Association Committee, 1998). This express a liberal feminist idea that discriminating women in life opportunities, does not allow them to have equal status with men. If one takes a mental survey of women in all sectors of the Nigerian society, one realizes that men have dominated everywhere; women exist in very few sectors of our economy. Hence, limit the degree of contribution they can offer in the development of the country.

\section{(c) Gender needs}

Practical gender needs according to Moser, (1989) are the immediate needs identified by women to assist their survival in their socially accepted roles, within existing power structures. This guarantees women and their families adequate living conditions, such as health care, food, shelter, clothing and access to safe water and sanitation. In Nigeria, some societies, give women the roles of farming. The women cultivate and harvest the end products back to the family, while the man does nothing. In such communities, it is the responsibility of the woman to cater for the needs of the children simply because the culture predestined the woman to perform such roles.

\section{(d) Gender Planning}

The purpose of gender planning is to ensure the production of gender sensitive policy outcomes. The gender planning as political process requires consultations and participation of different stakeholders, there is a variety of gender planning framework based on differing approaches in gender analysis, each with its own planning principles and tools. Caroline, (1993) developed a gender planning framework consisting of gender planning tools, which include: gender roles identification, gender needs assessment and the collection of disaggregated data at the house hold level. What planning does Nigeria offer to women? Even if there are such plans, it is not implemented to conclusive end. Indeed, the manease of bribery and corruption which characterized the people on authority, have made it practically impossible to implement any development plan in Nigeria.

\section{(e) Gender relations}

The hierarchical relation of power between men and women has not been favourable to women (Pearson \& Jackson, 1998) the gender hierarchies are often accepted as natural, but in reality they are socially determine relations, culturally based and are subject to change over time. These are common in division of labour and resource analysis which focus on gender relation. The interaction of gender relations with other hierarchical social relations such as class, ethnicity and race. It is a common practice world over for men to rape or physically abuse women. Nigeria is not an exception, where women are expose to danger of rape and demostic violence.

\section{(f) Gender training}

The process of training into the work of development and skill acquisition, do not favour women, in most cases, women are not given the same opportunity in this process. As awareness grows within an organization, so the emphasis of gender training is directed towards providing a balance between men and women, most families, particularly in Northern Nigeria prefer to get their daughters married immediately after completing secondary school. This trend has created a shortfall in the number of women that are eligible for training in areas like medicine, administration, engineering and politics etc.

\section{(g) Gender violence}

It is an act or threat by men or male dominated institution that inflicts physical, sexual or psychological harm on women or girl because of their gender (British council, 1999) gender violence is a common activity in both public and private sectors. This is something we witness in every society. Women have continuously become unsecured from men they know. Nigeria as a nation also witnesses one form of gender violence or the other. 
(h) Intra-household resource distribution

The dynamics of how different resources that are generated within or which come into the household are controlled and assessed by men (Evans, 1991) these patterns are not universal, but in a country like Nigeria, particularly in the eastern part of the country, is a common practice. Whenever the head of the household dies, the relations of the husband take over everything, living the wife and children with virtually nothing. In the extreme, the wife is sometimes accused of killing her husband, resulting in taking an oath to prove her innocence.

\section{(i) Sex and gender}

Sex refers to the biological characteristics that categorize someone as either male or female (Baden \& Goetz, 1998) women's marginalization has often been seen as natural. However, their biological differences cannot explain why women have less access to power and higher status.

Gender is how a person's biology is culturally valued and interpreted into locally accepted idea of what it is to be a woman or man. Hence, gender and hierarchical power relations between man and woman based on this are socially constructed and not derived directly from biology. Even countries with developed democracies like U.S.A, France and Britain hardly have women as head of states.

\section{Curriculum roles in Neutralizing gender inequality}

In a situation where a society faces a serious social problems, one of the easy channels to check them is through the educational system. In this approach, the society injects curriculum aspects in the educational system in order to create a well balanced society. Nigeria too, can borrow a lead from this assertions. If the nation can innovate aspects related to gender inequality, and develop a curriculum outlook, it will go a long way in reducing the rate of inequality between man and woman.

In gender division of labour, we need to give the woman a chance to work and contribute to the wellbeing of the family. Therefore, the educational system should identify areas where the woman can contribute i.e. education of children, feeding and health care, clothing etc if the woman is given such roles, the husband will understand the need for her to have a source of income.

In gender equality and equity, we need to develop a curriculum programme right from secondary school that will orient our women to endeavour to be in all works of life like men. We have to teach our women folk that there is no work designated for man. The educational system has to create a positive confidence in the woman to feel she can deliver as a man.

The educational system too, through the curriculum progrmme, has to expose the woman to the fact that, she has needs for health care, food, shelter, clothing and access to safe water. Hence, we need curriculum aspects that will show to women these are necessities in life.

There should be curriculum aspects teaching family the need for planning. Through this both husband and wife will join heads together and contribute in the process of acquisition of family property like car, house, furniture and savings etc.

There is need for curriculum exposure that will protect the woman from rape and physical abuse. This can be possible by teaching women how to defend themselves from such act. There are many techniques, that can be taught to the women to protect herself from these social problems.

Women through the curriculum programme have to be given a training in skill acquisition, it is important for the educational system to remove the dichotomy between man and woman in the process of skill acquisition.

The woman has right to family resources therefore, we have to have a curriculum exposure to our women to understand that, they have a right to inheritance, the ignorance of our women which has been motivated by cultural practices has to be checked through the educational system.

\section{Recommendation}

The following recommendation are advanced in order to enhance gender equality in Nigeria.

(1) Culture is not static, but dynamic in nature. Therefore, the cultural practices in our communities, should favour man and woman to a reasonable degree.

(2) Couples must be educated by our Islamic and Christian clerics on children, either male or female should be considered as a gift of nature.

(3) Nigeria should have a legislative act that will determine the appropriate number of wives a man marries, in accordance to the provisions of the major religions in Nigeria.

(4) Nigeria needs to have a law that will give women a reasonable representation in public life from local to federal governments.

(5) Nigeria needs a strict and harsh law that will punish a man that inflicts pain, either through rape, violence, neglect to the woman race. 
(6) There should be an inheritance law designated to protect women and their children in our communities, where there is no specific law of inheritance.

\section{Conclusion}

In conclusion, there is no doubt, women have a role to play in social and economic security in Nigeria, however, these roles cannot be accomplished without removing all forms of inequality against the women in our nation. Inequality between sexes, even where such inequalities do not have any moral and religious justifications. Segregation in labour distribution that does not justify right position of man and woman, unequal treatment to women simply because they are weaker sex, disregard to woman basic needs, due to the domineering attitude of men, inadequate training to a woman, due to mental picture a man has, that a woman cannot perform as good as a man are creating a serious problems in our social and economic development as a nation, which generates in the state of insecurity in nation. In order to have a balance society socially and economically, we have see that all forms of gender inequality are eradicated in Nigeria.

\section{References}

[1] Anker, R (1997). Gender and jobs sex segregation of occupations in the world. L.O. Geneva.

[2] Baden, S. and Goetz, A. (1998). Who needs (sex) when you can have gender: conflicting discourses on gender at Beijing. Rutledge London.

[3] British Council (1998). Introduction, interrogating feminism, gender and policy. Rutledge, London.

[4] Evans, A (1991). Gender issues in rural household economics. IDS Bulletin, Vol. 22 No.1.

[5] Harcourt, W. (1997). The search for social justice development. Vol. $40 \mathrm{pp}$

[6] 5.11. The society for international development: SAGE Publications, London.

[7] Moser, C. (1989). Gender Planning and development: theory, practice and training. Rutledge, London.

[8] Moser, C. (1998). Gender Planning and development: Theory, practice and training. Rutledge, London.

[9] Pearson, R. and Jackson, C. (1998). Introduction, interrogating, feminism, gender and policy. Rutledge, London. 